\title{
Nitric oxide synthesis in patients with infective gastroenteritis
}

\author{
P Forte, R S Dykhuizen, E Milne, A McKenzie, C C Smith, N Benjamin
}

\begin{abstract}
Background-There is evidence that endogenous nitrate synthesis is notably increased in patients with infective gastroenteritis.

Aims-To determine whether this is due to nitric oxide (NO) production via the L-arginine/NO pathway.

Methods-Seven male patients with community acquired bacterial gastroenteritis and 15 healthy male volunteers participated in this study. All patients had stool culture positive infective gastroenteritis. A bolus of $200 \mathrm{mg} \mathrm{L}-\left[{ }^{15} \mathrm{~N}\right]_{2}$-arginine was administered intravenously after an overnight fast. Urine was collected for the next 36 hours. Urinary $\left[{ }^{15} \mathrm{~N}:{ }^{14} \mathrm{~N}\right]$ nitrate ratio was assessed by dry combustion in an isotope ratio mass spectrometer.

Results-Mean 36 hour total urinary nitrate excretion in the gastroenteritis group was 5157 (577) $\mu \mathrm{mol}$ compared with 2594 (234) $\mu \mathrm{mol}$ in the control group $(p<0.001)$. Thirty six hour urinary $\left[{ }^{15} \mathrm{~N}\right] \mathrm{ni}-$ trate excretion was considerably higher in the gastroenteritis group compared with the control group (13782 (1665) versus 1698 (98) $\eta \mathrm{mol} ; \mathrm{p}<0.001)$. These values represent $1.129(0.139) \%$ and 0.138 $(0.007) \%$ of $\left[{ }^{15} \mathrm{~N}\right]$ nitrogen administered $(\mathbf{p}<0.001)$, respectively. Corrected 36 hour urinary $\left[{ }^{15} \mathrm{~N}\right]$ nitrate excretion for urinary creatinine was also significantly higher in the patient compared with the control group (1934 (221) versus 303 (35) $\eta \mathrm{mol} /$ mmol; $\mathbf{p}<0.001)$.

Conclusion-Results show notably enhanced nitrate synthesis due to increased activity of the L-arginine/NO pathway in patients with infective gastroenteritis. (Gut 1999;45:355-361)
\end{abstract}

Keywords: endothelium derived relaxing factor; $\mathrm{L}-\left[{ }^{15} \mathrm{~N}\right]_{2}$-arginine; nitrates; infection; diarrhoea

Nitric oxide (NO) is synthesised from the guanidino nitrogen atoms of L-arginine by $\mathrm{NO}$ synthase (NOS). ${ }^{1}$ Three isoforms of NOS have been identified: an endothelial type (eNOS), a neuronal type (nNOS), and a macrophage (inducible, iNOS) type. Both nNOS and eNOS tend to be expressed constitutively; however, iNOS expression generally requires induction under the influence of various cytokines and/or lipopolysaccharide (LPS). ${ }^{2}$ Several studies have shown the existence of a cytokine inducible high output L-arginine/NO pathway in humans. Ochoa et al reported a ninefold increase in plasma nitrate concentrations in patients with cancer receiving interleukin $2 .^{3}$ Furthermore, Hibbs et al, using $\mathrm{L}-\left[{ }^{15} \mathrm{~N}\right]_{2^{-}}$ guanidino arginine as a metabolic tracer, showed that this increase in nitrate synthesis is by activation of the L-arginine/NO pathway. ${ }^{4}$ Moreover, Sherman et al showed the expression and the isolation of cDNA for a cytokine induced NOS in a transformed human intestinal epithelial cell line, ${ }^{5}$ a finding which has been confirmed by other independent investigators. ${ }^{67}$

Increasing data indicate that $\mathrm{NO}$ exerts important antimicrobial activity against a wide range of pathogenic microorganisms. ${ }^{8}$ For instance, inhibitors of NOS exacerbate infection in vitro and in vivo against enterobacteria such as Escherichia coli and Salmonella sp., ${ }^{9}$ and iNOS deficient mice are highly susceptible to infections with Leishmania major and Listeria monocytogenes. ${ }^{10}$ Conversely, accumulating evidence also suggests that reactive species derived from NOS play a significant role in acute and chronic inflammation. Recently, several reports have suggested that overproduction of NO could play an important role in the pathogenesis of inflammatory bowel disease (IBD). Indeed, increased levels of $\mathrm{NO}$ and iNOS activity have been shown in the colonic lumen and mucosa of patients with ulcerative colitis. ${ }^{11-13}$ Furthermore, inhibitors of NOS have been shown to exert a protective role in ileitis induced by trinitrobenzene sulphonic acid in guinea pigs $^{14}$ and rats. ${ }^{15}$ In addition, iNOS deficient mice generate significantly less footpad swelling after injection with carrageenin and are also more resistant to LPS induced death than wild type. ${ }^{10}$

Nitric oxide in blood is rapidly oxidised to nitrate by oxygenated haemoglobin, molecular oxygen, and superoxide anions and is excreted as such into the urine. ${ }^{16}$ Hegesh and Shiloah ${ }^{17}$ showed in 1982 that infants with acute gastroenteritis had a notable increase in plasma nitrate concentration. Our group ${ }^{18}$ and Wagner and colleagues ${ }^{19}$ have previously reported a similar increase in plasma nitrate concentration and urinary nitrate excretion in adults with infective gastroenteritis. This increase in nitrate production was also much greater in patients with infective gastroenteritis than that seen with more severe inflammation caused by IBD. ${ }^{20}$ The main problem with the use of total nitrate production rate as a measure of $\mathrm{NO}$ synthesis is, however, that nitrate may arise from sources other than that generated from the metabolism of $\mathrm{NO}$ and dietary intake of

Abbreviations used in this paper: LPS, lipopolysaccharide; IBD, inflammatory bowel disease; NO, nitric oxide; NOS: nitric oxide synthase. 
nitrate may exceed endogenous production. ${ }^{21}$ Based on the calculated half life for nitrate in plasma (about eight hours), ${ }^{22}{ }^{23}$ diet restriction must be maintained for at least 40 hours (five half lives) in order to eliminate the confounding influence of exogenous nitrate/nitrite. It is not yet clear, however, whether all endogenous nitrate production results from $\mathrm{NO}$ oxidation. In previous studies, our group ${ }^{24}$ and Rhodes and colleagues ${ }^{25}$ reported that enrichment of ${ }^{15} \mathrm{~N}$ in urinary and plasma nitrate was lower than that seen in steady state plasma L- $\left[{ }^{15} \mathrm{~N}_{2}\right]-$ arginine, suggesting that endogenous production of nitrate may occur in humans.

To overcome these limitations, we have developed a sensitive and specific method of measuring the conversion of $\mathrm{L}$-arginine into NO. ${ }^{23}$ The method is based on the measurement of $\left[{ }^{15} \mathrm{~N}\right]$ nitrate excretion in urine after the intravenous administration of the stable isotope $\mathrm{L}-\left[{ }^{15} \mathrm{~N}\right]_{2}$-guanidino arginine. The aim of this study was to compare the activity of the $\mathrm{L}$-arginine/NO system more directly in patients with infective gastroenteritis and matched healthy controls.

\section{Materials and methods}

SUBJECTS

The study was carried out in the Infection Unit at Aberdeen Royal Infirmary. Permission was obtained from the local Ethics Committee and all subjects gave their written, informed consent before participating. Seven consecutive male patients (age 22-40 years) referred to the Unit with community acquired bacterial gastroenteritis were entered into the study. All patients had stool culture positive for infectious gastroenteritis: five with Campylobacter jejuni, one with Cryptosporidium, and one with Salmonella enteritidis. The control group consisted of 15 healthy male volunteers (age 21-41 years) from hospital and laboratory staff. All subjects were normotensive, non-diabetic, nonsmokers, and were receiving no medication. Table 1 presents the clinical characteristics of all subjects who took part in each protocol.

\section{TRACER INFUSION STUDY}

Healthy volunteers received a limited nitrate diet (the diet excluded food items which contain a high concentration of nitrate - that is, cured meat, fruit, and particularly, green leafy vegetables ${ }^{21}$ ) 24 hours before and for 36 hours after the administration of $\mathrm{L}-\left[{ }^{15} \mathrm{~N}\right]_{2}$-guanidino arginine. Patients were given only intravenous

Table 1 Baseline subject characteristics

\begin{tabular}{|c|c|c|}
\hline & Controls $(n=15)$ & Patients $(n=7)$ \\
\hline Age $(y)$ & $28.6(1.8)$ & $32.4 \quad(1.7)$ \\
\hline Weight (kg) & $75.5 \quad(2.2)$ & $77.1 \quad(3.1)$ \\
\hline Height (m) & $1.78(0.03)$ & $1.81(0.06)$ \\
\hline Body mass index $\left(\mathrm{kg} / \mathrm{m}^{2}\right)$ & $23.9 \quad(1.1)$ & $23.7(1.4)$ \\
\hline $\begin{array}{l}\text { Systolic blood pressure } \\
(\mathrm{mm} \mathrm{Hg})\end{array}$ & $(1.21)$ & 122 \\
\hline $\begin{array}{l}\text { Diastolic blood pressure } \\
\quad(\mathrm{mm} \mathrm{Hg})\end{array}$ & $68.5 \quad(1.4)$ & $(4.5)$ \\
\hline $\begin{array}{l}\text { Mean arterial blood } \\
\text { pressure }(\mathrm{mm} \mathrm{Hg})\end{array}$ & $87.1 \quad(1.13)$ & $87.3(4.1)$ \\
\hline Glucose $(\mathrm{mmol} / \mathrm{l})$ & $4.7 \quad(0.15)$ & $4.8(0.4)$ \\
\hline $\begin{array}{l}\text { Creatinine clearance } \\
(\mathrm{ml} / \mathrm{min})\end{array}$ & 103.5 & 106.9 \\
\hline
\end{tabular}

Results expressed as mean (SEM). nitrate free fluid replacement solutions (a combination of $5 \%$ dextrose and $0.9 \%$ sodium chloride) throughout the first 24 hours of admission. Healthy volunteers were studied in the hospital ward under similar conditions to the patients. After an overnight fast, an 18 gauge catheter was inserted into a left antecubital vein and $200 \mathrm{mg}(1.13 \mu \mathrm{mol})$ sterile pyrogen free $\mathrm{L}-\left[{ }^{15} \mathrm{~N}\right]$, -guanidino arginine $(99 \mathrm{~mol} \%$ ${ }^{15} \mathrm{~N}$; Tracer Technologies, Massachusetts, USA) dissolved in $20 \mathrm{ml} 0.9 \%$ sodium chloride was administered over 10 minutes by means of a constant rate infusion pump (Braun Perfusor ED 2, Germany). Baseline urine samples (before administration of the isotope) were collected to determine the natural enrichment of $\left[{ }^{15} \mathrm{~N}\right]$ nitrate. Complete urine collections were made in prewashed (distilled water) two litre polypropylene bottles containing $5 \mathrm{ml}$ of 5 $\mathrm{mol} / 1$ sodium hydroxide to prevent reduction of nitrate for the periods $0-12,12-24$, and 24-36 hours after dosing. Healthy volunteers did not exercise during the study period, but usual ambulatory activity was permitted. The urine volume was measured, and samples from each collection were frozen at $-80^{\circ} \mathrm{C}$ until analysis.

ANALYTICAL METHODS

Measurement of total urinary nitrate

Total urinary nitrate was measured as previously described. ${ }^{26}$ Briefly, nitrate was reduced to nitrite in a copper/cadmium reduction column and subsequent Griess reaction, modified by replacing carrier fluid with $1.5 \%$ glycine, $\mathrm{pH}$ 9.4. The detection limit of this method is $1 \mu \mathrm{M}$ and interday coefficient of variation over the measured concentration range $(20-1000 \mu \mathrm{M})$ was less than $3 \%$.

\section{Measurement of $\left[{ }^{15} \mathrm{~N}:{ }^{14} \mathrm{~N}\right]$ nitrate ratio}

In order to determine ${ }^{15} \mathrm{~N}$ enrichment of nitrate in urine, a modification of the procedure described by Brooks and colleagues ${ }^{27}$ was followed. $^{23}$ Briefly, urinary nitrate was extracted using a selective ion exchange resin (IMAC HP555; Merck Laboratories, Domstadt, Germany), and converted to ammonia using $0.4 \mathrm{~g}$ Devarda's alloy (BDH, UK) in the presence of $0.2 \mathrm{~g}$ magnesium oxide (Sigma, St Louis, Missouri, USA) with subsequent conversion to nitrogen gas by combustion at $1000^{\circ} \mathrm{C}$, and analysis by continuous flow gas isotope ratio mass spectrometry (20-20, Europa Scientific, UK). The precision of ${ }^{15} \mathrm{~N}:{ }^{14} \mathrm{~N}$ ratio measurement of this mass spectrometer is $\pm 0.0004 \%$. The linearity of the measurements was shown across the range of the expected enrichments (0.368-1 atom \%) with a correlation coefficient of 0.999 by linear regression analysis. The interday coefficient of variation ranged from $0.41 \%$ to $0.78 \%$.

CALCULATIONS AND STATISTICAL ANALYSIS Total urinary nitrate excretion was calculated from the volume of urine excreted and duplicate measurement of urinary nitrate concentration. The $\left[{ }^{15} \mathrm{~N}\right]$ isotope enrichment of nitrate was calculated according to Hauck and colleagues $^{28}$ :

Atom per cent ${ }^{15} \mathrm{~N}=100 /(2 \mathrm{R}+1)$ 
Table 2 Urinary excretion of total nitrate and $\left[{ }^{15} \mathrm{~N}\right]$ nitrate following a $200 \mathrm{mg}$ intravenous dose of $L-\left[{ }^{15} \mathrm{~N}_{2}\right]$ arginine in healthy volunteers $(n=15)$ and patients with infective gastroenteritis $(n=7)$

\begin{tabular}{|c|c|c|c|c|c|c|}
\hline Time & $\mu \mathrm{mol} \mathrm{NO}_{3}$ & At $\%$ & At $\%$ excess & $\eta m o l ~\left[{ }^{15} \mathrm{~N}\right] \mathrm{NO}_{3}$ & $\begin{array}{l}\eta_{15 \mathrm{~mol}} \\
{ }^{15} \mathrm{~N} / \mathrm{NO}_{3} / \mathrm{mmol} \\
\text { creatinine }\end{array}$ & $\begin{array}{l}\text { Recovery of } \\
\left.{ }^{15} \mathrm{~N}\right] \text { nitrogen (\% } \\
\text { of admin. } \\
{ }_{L}-\left[{ }^{15} \mathrm{~N}_{2}\right] \text { arginine) }\end{array}$ \\
\hline \multicolumn{7}{|l|}{ Control group } \\
\hline $0-12 \mathrm{~h}$ & $986(150)$ & $0.4731(0.029)$ & $0.1052(0.03)$ & $1056.1(55)$ & $188.9(26)$ & $0.086(0.005)$ \\
\hline $12-24 \mathrm{~h}$ & $732(94)$ & $0.4360(0.012)$ & $0.0620(0.012)$ & $434.4(45)$ & $75.6(9)$ & $0.035(0.004)$ \\
\hline $24-36 \mathrm{~h}$ & $815(125)$ & $0.4005(0.006)$ & $0.0281(0.006)$ & $197.5(17)$ & $38.9(4)$ & $0.016(0.005)$ \\
\hline Total $(0-36 \mathrm{~h})$ & $2594(234)$ & & & $1698.1(98)$ & $303.4(35)$ & $0.138(0.007)$ \\
\hline \multicolumn{7}{|c|}{ Gastroenteritis group } \\
\hline $0-12 \mathrm{~h}$ & $2764(476)$ & $0.7395(0.026)$ & $0.3708(0.025)$ & $10033.1(1584)^{\star}$ & $1269.7(167)^{\star}$ & $0.822(0.12)^{\star}$ \\
\hline $12-24 \mathrm{~h}$ & $1262(182)$ & $0.5760(0.014)$ & $0.2073(0.014)$ & $2573.5(366)^{\star}$ & $444.8(114)^{\star}$ & $0.211(0.03)^{\star}$ \\
\hline $24-36 \mathrm{~h}$ & $1132(95)$ & $0.4741(0.013)$ & $0.1054(0.013)$ & $1176.1(169)^{\star}$ & $220.2(44)^{\star}$ & $0.096(0.01)^{\star}$ \\
\hline Total $(0-36 \mathrm{~h})$ & $5157(577)^{\star}$ & & & $13782.6(1665)^{\star}$ & $1934(221)^{\star}$ & $1.129(0.139)^{\star}$ \\
\hline
\end{tabular}

${ }^{\star} \mathrm{p}<0.001$.

where $\mathrm{R}=$ ratio of ions with $\mathrm{m} / \mathrm{z} 28$ and 29. Urinary excretion of $\left[{ }^{15} \mathrm{~N}\right]$ nitrate was determined by measuring the total urinary nitrate excretion multiplied by the measured atom per cent excess of urinary $\left[{ }^{15} \mathrm{~N}\right]$ nitrate. A one compartment pharmacokinetic model was used to analyse the urinary data obtained in this study. The total elimination rate was determined by a single pool kinetic equation. ${ }^{29}$ All values are presented as mean (SEM). Statistical analysis was performed using the unpaired Student's $t$ test on log transformed measurements of urinary $\left[{ }^{15} \mathrm{~N}\right]$ nitrate excretion in the two study populations. A value of $\mathrm{p}<0.05$ was considered significant.

\section{Results}

Mean 36 hour total urinary nitrate excretion in the gastroenteritis group was 5157 (577) $\mu \mathrm{mol}$ compared with 2594 (234) $\mu \mathrm{mol}$ in the control group $(\mathrm{p}<0.001)$. Mean 36 hour urinary $\left[{ }^{15} \mathrm{~N}\right]$ nitrate excretion was significantly higher in the gastroenteritis group than in the control group (13782 (1665) versus 1698 (98) $\eta \mathrm{mol}$; $\mathrm{p}<0.001)$. These values represent 1.129 $(0.139) \%$ and $0.138(0.007) \%$ of $\left[{ }^{15} \mathrm{~N}\right]$ nitrogen administered $(\mathrm{p}<0.001)$, respectively, assuming one labelled guanidino nitrogen per arginine molecule is incorporated to nitrate. Corrected 36 hour urinary $\left[{ }^{15} \mathrm{~N}\right]$ nitrate excretion for urinary creatinine was also significantly higher in the patient than in the control group

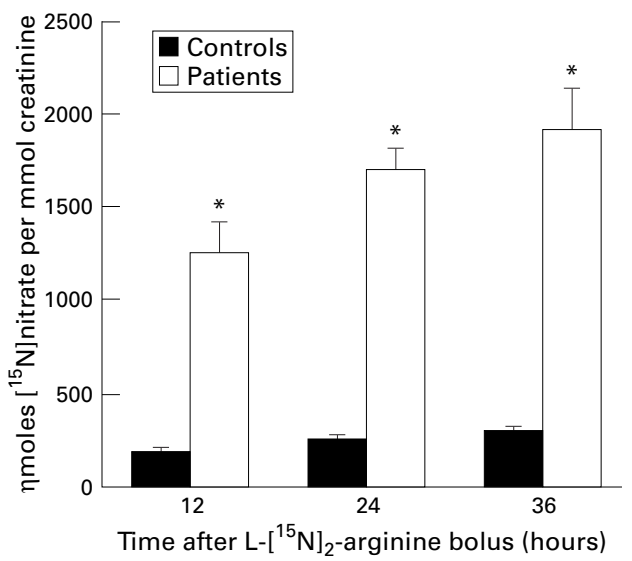

Figure 1 Cumulative urinary excretion of $\left[{ }^{15} \mathrm{~N}\right]$ nitrate after intravenous administration of $L-\left[{ }^{15} \mathrm{~N}\right]_{2}$-guanidino arginine in patients and controls. Values are mean (SEM) for seven patients and 15 healthy volunteers. * Significant difference between healthy volunteers and patients $(p<0.001)$.
(1934 (221) versus 303 (35) $\eta \mathrm{mol} / \mathrm{mmol}$; $\mathrm{p}<0.001)$. Table 2 shows the urinary excretion of $\left[{ }^{15} \mathrm{~N}\right]$ nitrate in each 12 hour period after the administration of $\mathrm{L}-\left[{ }^{15} \mathrm{~N}\right]_{2}$-arginine. Figure 1 shows the cumulative recovery of $\left[{ }^{15} \mathrm{~N}\right]$ nitrate in urine. The total elimination rates of nitrate in patients and healthy volunteers were similar $(-0.083 / \mathrm{h}$ and $-0.082 / \mathrm{h})$. Likewise, the urinary creatinine clearance was similar in both groups (106.1 (2.5) versus $103.2(2.4) \mathrm{ml} / \mathrm{min}$, respectively).

\section{Discussion}

The results of this study show, for the first time, that the considerable increase in endogenous nitrate production in patients with infective gastroenteritis is due to oxidation of L-arginine via NOS. The tissue location of the sevenfold increase in NO synthesis in this study cannot, however, be determined.

Direct measurement of NO production is difficult because of its short half life in vivo. ${ }^{16}$ In mammalian cells, NO is enzymatically synthesised from the guanidino nitrogen atoms of L-arginine, and this is the only known enzymatic biochemical route by which these nitrogen atoms may be incorporated into nitrate. ${ }^{1}$ Determination of the urinary excretion of $\left[{ }^{15} \mathrm{~N}\right]$ labelled nitrate following intravenous administration of $\mathrm{L}-\left[{ }^{15} \mathrm{~N}\right]_{2}$-guanidino arginine is therefore independent of nitrate excretion from dietary or other unknown endogenous sources. The notable finding in this study was that the mean 36 hour urinary $\left[{ }^{15} \mathrm{~N}\right]$ nitrate excretion was significantly higher in patients with infective gastroenteritis than in healthy volunteers after systemic administration of $\mathrm{L}-\left[{ }^{15} \mathrm{~N}\right]_{2}$-guanidino arginine. We considered that an alteration in the renal clearance of nitrate in the study groups may explain the observed difference. However, urinary $\left[{ }^{15} \mathrm{~N}\right] \mathrm{ni}-$ trate excretion was assessed over 36 hours (more than $90 \%$ of generated nitrate was excreted). In addition, the mean elimination constants of nitrate were similar in both groups, as was the creatinine clearance. Therefore, differences in renal handling of nitrate are unlikely to explain the difference in $\left[{ }^{15} \mathrm{~N}\right]$ nitrate excretion.

We also contemplated the possibility that the $\left[{ }^{15} \mathrm{~N}\right]$ nitrate synthesised came from metabolism of $\mathrm{L}-\left[{ }^{15} \mathrm{~N}\right]_{2}$-arginine by intestinal microflora (i.e. the NOS present in these organisms). This is, however, unlikely to explain the large differ- 
ence observed between the two groups, as $\mathrm{L}-\left[{ }^{15} \mathrm{~N}\right]_{2}$-arginine was administered intravenously. In addition, Smith and MacFarlane recently reported that the metabolism of $\mathrm{L}$-arginine by human intestinal bacteria involves the arginine deaminase pathway as the exclusive pathway of catabolism. ${ }^{30}$ This pathway includes the combined activity of the enzymes, arginine deaminase, ornithine transcarbamylase, and carbamate kinase, which catalyses the conversion of L-arginine to ornithine, ammonia, and carbon dioxide with the concurrent formation of ATP. ${ }^{31}$ This indicates that the guanidino amino groups of L-arginine are primarily metabolised to ammonia, which may subsequently be used as a cellular nitrogen source during bacterial growth. Moreover, as the enzymatic synthesis of NO requires consumption of molecular oxygen, ${ }^{32}$ this hypothetical L-arginine/NO pathway in intestinal bacteria would not be favoured under the anaerobic conditions present in the intestinal lumen. ${ }^{33}$

However, there are reports suggesting that enteric bacteria could generate nitrate. ${ }^{34}$ Ioannidis et $a l$ and Crawford and Goldberg have reported in enterobacteria such as $E$ coli and Salmonella $\mathrm{sp}$. the presence of an inducible flavohaemoglobin that metabolises $\mathrm{NO}$ to nitrate. ${ }^{35} 36$ Nitric oxide reacts with the haem group of this protein and is metabolised to nitrate by an oxidoreductase reaction. Although the role of this bacterial haemoglobin is still unknown, it may represent a cellular protective mechanism against nitrosative stress exerted by NO and nitrosothiols. ${ }^{37}$ This pathway could, therefore, constitute a novel enzymatic pathway of nitrate generation by enterobacteria in the intestinal lumen. However, this source of nitrate would not affect the results obtained in the present study, as $\left[{ }^{15} \mathrm{~N}\right]$ nitrate generated from $\mathrm{L}-\left[{ }^{15} \mathrm{~N}\right]_{2}$-arginine is independent of other pathways of nitrate generation. As the healthy volunteers were ambulant while the patients were in the hospital ward and in bed, it is possible that ambulatory related vasodilatation might have affected the results obtained. Nevertheless, this difference would tend to underestimate the whole body conversion of $\mathrm{L}-\left[{ }^{15} \mathrm{~N}\right]_{2}$-arginine to $\left[{ }^{15} \mathrm{~N}\right] \mathrm{ni}$ trate in the patient group, as they were confined to bed and exercise is known to increase $\mathrm{NO}$ synthesis. ${ }^{38}$ As the subjects were of similar age and body mass index, and were normotensive, non-smokers, and non-diabetic, the most likely explanation of our findings is that the production of $\left[{ }^{15} \mathrm{~N}\right]$ nitrate after the intravenous administration of $\mathrm{L}-\left[{ }^{15} \mathrm{~N}\right]_{2}$-arginine is higher in infective gastroenteritis than in healthy controls under basal conditions.

In this study, the site from which $\left[{ }^{15} \mathrm{~N}\right]$ nitrate derives cannot be determined, nor can we establish whether the source of nitrate is from a constitutive or inducible NOS. The sevenfold increase in urinary $\left[{ }^{15} \mathrm{~N}\right]$ nitrate excretion observed in patients with gastroenteritis does, however, suggest that the high output iNOS could be the major source of $\mathrm{NO}$ production in this condition. Intestinal epithelial cells are known to respond to bacterial invasion with the production of a range of proinflammatory cytokines. ${ }^{39}$ It is likely, therefore, that the increase in NO production could have derived from infiltrating inflammatory cells (macrophages and neutrophils), epithelial cells, endothelial or vascular smooth muscle cells, or other mucosal cells. Indeed, studies in vitro have shown that infection of human colonic epithelial cells with enteroinvasive bacteria activates epithelial cell iNOS expression and NO production. ${ }^{40}{ }^{41}$ Moreover, Islam et al and Kolios et al showed in biopsy specimens of patients with acute shigella and salmonella colitis, increased expression of iNOS in intestinal epithelial cells. ${ }^{42} 43$

There is also a growing body of experimental evidence suggesting that the expression of iNOS is upregulated in the colon of patients with IBD. Lundberg et al found NO concentrations in luminal gas sampled from the colon 100 times higher in patients with active ulcerative colitis than in controls. ${ }^{13}$ Middleton et al showed high concentrations of L-citrulline, coproduct of the conversion of L-arginine to NO, in rectal biopsy specimens from patients with active ulcerative colitis. ${ }^{11}$ Furthermore, several groups have reported a significant increase in calcium independent NOS activity in the colonic mucosa of patients with active ulcerative colitis and Crohn's disease. ${ }^{1244} 45$ Other investigators have also shown increased expression of iNOS in the surface epithelium of colonic mucosa from patients with ulcerative colitis. ${ }^{43} 47$ Moreover, recent data have confirmed that iNOS mRNA is upregulated in adults and children with IBD. ${ }^{48}$ Taken together, these data suggest that the increased levels of NO in the colon of patients with infective gastroenteritis and IBD could result from high expression of iNOS.

However, there are also reports of increased NO production by calcium dependent NOS in the colon of patients with Crohn's disease ${ }^{45}$ and megacolon due to ulcerative colitis, ${ }^{50}$ suggesting the possibility that activation of cNOS may also contribute to the overproduction of $\mathrm{NO}$ in infective gastroenteritis. Further studies are necessary to determine whether the increased $\mathrm{NO}$ production in infective gastroenteritis is from an inducible and/or constitutive NOS. In a previous study we observed that the whole body NO synthesis did not increase after typhoid vaccination in humans, even when there was clear evidence for an inflammatory response in terms of fever, peripheral blood white cell count, and plasma C-reactive protein. ${ }^{25}$ We suggest that acute infective gastroenteritis is a strong inflammatory stimulus to increase NO production mediated by either luminal bacterial products or intramucosal release of cytokines such as tumour necrosis factor $\alpha$, interleukin $1,{ }^{51}$ interleukin $2,{ }^{4}$ and interferon $\gamma .{ }^{40}$

Further studies are required to determine the role of this overproduction of $\mathrm{NO}$ in infective gastroenteritis. However, we consider that this increase in NO production could represent a mechanism for limiting tissue injury from infection. In line with this proposition, we have reported in patients with infective gastroenteritis 
that plasma nitrate concentrations correlated positively with the clinical severity of the infection, and the levels of plasma nitrate decreased as the patients recovered from illness. ${ }^{20}$ Likewise, Islam et al and Kolios et al reported that iNOS expression in colonic surface epithelium was significantly reduced at convalescence, when all patients' stool cultures were negative for infecting agents. ${ }^{42}{ }^{43}$ It is not clear how NO exerts intracellular inhibition of bacteria, but NO has been shown to inhibit mitochondrial respiration by inactivation of complex I and complex II of the electron transport chain and the aconitase of the Krebs cycle. ${ }^{52}$ In addition, there is increasing evidence to suggest that bactericidal activity against a number of targets is mediated by the reaction of $\mathrm{NO}$ and reactive oxygen intermediates. ${ }^{534}$ Nitric oxide may also contribute to host defence in infective gastroenteritis by securing blood flow to tissues with increased metabolic needs and by modulating intestinal epithelial permeability. ${ }^{55}$

Another possible mechanism by which increased NO synthesis could protect against bacterial invasion is by increasing the enterosalivary circulation of nitrate. Indeed, we have shown that salivary nitrate is rapidly reduced to nitrite by lingual bacteria, ${ }^{56}$ and subsequently high concentrations of $\mathrm{NO}$ are generated by chemical reduction of nitrite in the stomach. ${ }^{57}$ Our group has also shown in vitro the bactericidal effect of acidified nitrite (in concentrations similar to those found in saliva) on the different microorganisms involved in the aetiology of infective gastroenteritis. ${ }^{58}$ Therefore, this pathway may protect the host against faecal-oral reinfection, transmission of infection, and the development of a chronic carrier state. However, there is also evidence suggesting that gut mucosal injury and bacterial translocation across the intestinal tract may be mediated through increased NO production by activated iNOS. For instance, Mishima et al and Sorrels et al have shown in rats that LPS induced mucosal injury and bacterial translocation could be prevented by the administration of L-NMMA ${ }^{59}$ and aminoguanidine ${ }^{60}$ (a selective inhibitor for iNOS). Furthermore, Mishima et al recently showed that endotoxin induced gut injury and bacterial translocation was significantly higher in the wild type NOS $+/+$ mice than in the iNOS deficient mice. However, they did not find any difference in the degree of bacterial translocation, and the extent of mucosal injury between these strains in a model of intestinal bacterial overgrowth. ${ }^{61}$ Likewise, Laubach et al did not observe any difference in survival between iNOS $+/+$ and iNOS deficient mice treated with LPS. ${ }^{62}$

However, McCafferty et al reported that iNOS deficient mice were more susceptible to a mild colonic insult than their wild type controls, and also lacked the capacity to heal. ${ }^{63}$ Furthermore, Horton et al showed that parenteral supplementation of L-arginine reduced bacterial translocation through an $\mathrm{NO}$ dependent mechanism. ${ }^{64}$ The reasons for the discrepancies observed in these studies are not apparent, but possible explanations include the use of different models of bacterial transloca- tion, differences in genetic backgrounds, and use of different endotoxin concentrations. Regardless of the exact nature of these disparities, the extrapolation of these results to humans should be considered with caution, as the reported data in those murine models may not reflect bacterial translocation in the acute setting of human infective gastroenteritis.

It is also unclear whether the increased NO production in IBD is beneficial or harmful. NO may protect the intestinal mucosa and microvasculature against the multiple damaging factors involved in inflammation. For instance, NO prevents leucocyte-endothelial cell adhesion in postcapillary venules and emigration to the intestinal mucosa ${ }^{65}$ thereby limiting an important source of toxic reactive oxygen metabolites. In addition, $\mathrm{NO}$ could play an important role in host defence against bacterial invasion and intramural penetration of the colonic wall. The idea of a protective role of NO in IBD has been sustained by a recent study which showed that iNOS deficient mice developed more severe inflammation than wild type controls in an experimental model of colitis. ${ }^{63}$

Conversely, there are growing experimental and clinical indications suggesting that enhanced production of NO is related to microvascular damage and to the extent of tissue injury observed in IBD. Kimura et al showed a positive correlation between iNOS activity and disease severity, based on histological evidence in the colonic mucosa of patients with active ulcerative colitis. ${ }^{45}$ Furthermore, it was also found that the rate of nitrotyrosine (reaction product between NO derived oxidants and protein tyrosines) staining in the colonic mucosa increased proportionally with disease severity. ${ }^{47}$ Ouderk Pool et al reported that serum nitrate concentrations correlated with inflammatory variables and disease activity indexes. ${ }^{66} \mathrm{McLaughlan}$ et al showed a moderate correlation between polymorphonuclear cell infiltration and interleukin 8 and iNOS mRNA levels in colonic mucosal biopsy specimens from untreated patients with ulcerative colitis and Crohn's disease. ${ }^{48}$

Mechanisms by which excess production of NO may promote tissue injury and inflammation in IBD include inhibition of DNA synthesis $^{534}$ and mitochondrial function, ${ }^{52}$ release of intracellular iron, ${ }^{67}$ relaxation of colonic smooth muscle, ${ }^{50}$ and generation of carcinogenic nitrosamines. ${ }^{68}$ Taken together, it does seem that the acute and increased NO synthesis observed in infective gastroenteritis may mainly to control the infectious process, whereas the chronic and sustained overproduction of NO in IBD may contribute to cellular toxicity by overflowing the intestinal mucosa's antioxidant buffer capacity, and rendering the mucosa more susceptible to microvascular damage and tissue injury.

In summary, the results reported here suggest that infective gastroenteritis is a potent inflammatory stimulus of intestinal production of NO in humans. Further studies are needed to determine the role of this NO overproduction, and whether this source is from a constitutive and/or inducible NOS. 
This study was supported by the Joint Research Board at St Bartholomew's Hospital (Project XMLH).

1 Marletta MA, Yoon PS, Iyengar R, et al. Macrophage oxidation of L-arginine to nitrite and nitrate: nitric oxide is an tion of L-arginine to nitrite and nitrate: nitric
intermediate. Biochemistry 1988;27:8706-11.

2 Shultz PJ, Tayeh MA, Marletta MA, et al. Synthesis and action of nitric oxide in rat glomerular mesangial cells. $A m$ f Physiol 1991;261:F600-6.

3 Ochoa JB, Curti B, Peitzman AB, et al. Increased circulating nitrogen oxides after human tumor immunotherapy: correlation with toxic hemodynamic changes. I Natl Cancer Inst 1992;84:864-7.

4 Hibbs JB Jr, Westenfelder C, Taintor R, et al. Evidence for cytokine-inducible nitric oxide synthesis from $\mathrm{L}$-arginine in patients receiving interleukin-2 therapy. $\mathcal{F}$ Clin Invest 1992 ; 89:867-77.

5 Sherman PA, Laubach VE, Reep BR, et al. Purification and cDNA sequence of an inducible nitric oxide synthase from a human tumour cell line. Biochemistry 1993;32:11600-5.

6 Jenkins DC, Charles IG, Baylis SA, et al. Human colon cancer cell lines show a diverse pattern of nitric oxide synthase gene expression and nitric oxide generation. $\mathrm{Br} \mathcal{F}$ Cancer 1994; 70:847-9.

7 Salzman A, Denenberg AG, Ueta I, et al. Induction and activity of nitric oxide synthase in cultured human intestinal epithelial monolayers. Am f Physiol 1996;270:G56573.

8 DeGroote MA, Fang FC. NO inhibitions: antimicrobial properties of nitric oxide. Clin Infect Dis 1995;21:S162-5.

9 DeGroote MA, Granger D, Xu Y, et al. Genetic and redox determinants of nitric oxide cytotoxicity in a Salmonella typhimurium model. Proc Natl Acad Sci USA 1995;92:

10 Wei XQ, Charles IG, Smith A, et al. Altered immune responses in mice lacking inducible nitric oxide synthase. responses in mice lacking
Nature 1995;375:408-11.

11 Middleton SJ, Shorthouse M, Hunter JO. Increased nitric oxide synthesis in ulcerative colitis. Lancet 1993;341:465-6.

12 Boughton-Smith NK, Evans SM, Hawkey CJ, et al. Nitric oxide synthase activity in ulcerative colitis and Crohn's disease. Lancet 1993;342:338-40.

13 Lundberg JO, Hellström PM, Lundberg JM, et al. Greatly increased luminal nitric oxide in ulcerative colitis. Lancet 1994;344:1673-4.

14 Miller MJ, Sadowska-Krowicka H, Chotinaruemol S, et al. Amelioration of chronic ileitis by nitric oxide synthase inhibition. F Pharmacol Exp Ther 1993;264:11-16.

15 Rachmilewitz D, Karmeli F, Okon E, et al. Experimental colitis is ameliorated by inhibition of nitric oxide synthase colitis is ameliorated by inhibitio
activity. Gut 1995;37:247-55.

16 Wennmalm A, Benthin G, Edlund A, et al. Metabolism and excretion of nitric oxide in humans. An experimental and excretion of nitric oxide in humans. An
clinical study. Circ Res 1993;73:1121-7.

17 Hegesh E, Shiloah J. Blood nitrates and infantile methemoglobinemia. Clin Chim Acta 1982;125:107-15.

18 Dykhuizen RS, Copland M, Smith CC, et al. Plasma nitrate concentration and urinary nitrate excretion in patients with gastroenteritis. F Infect 1995;31:73-5.

19 Wagner DA, Young VR, Tannenbaum SR, et al. Mammalian nitrate biochemistry: metabolism and endogenous synthesis. IARC Sci Publ 1984;57:247-53.

20 Dykhuizen RS, Masson J, McKnight G, et al. Plasma nitrate concentration in infective gastroenteritis and inflammatory bowel disease. Gut 1996;39:393-5.

21 National Academy of Sciences Committee on Nitrate and Alternative Curing Agents in Food. The health effects of nitrate, nitrite and $N$-nitroso compounds. Washington DC: National Academy Press, 1981.

22 Jüngersten L, Edlund A, Petersson AS, et al. Plasma nitrate as an index of endogenous nitric oxide formation in man. Analysis of kinetics, confounding factors, and response to immunological challenge. Clin Physiol 1996;16:369-79.

23 Forte $\mathrm{P}$, Copland M, Smith LM, et al. Basal nitric oxide synthesis in essential hypertension. Lancet 1997;349:83742.

24 Macallan DC, Smith LM, Ferber J, et al. Measurement of NO synthesis in humans by L- $\left[{ }^{15} \mathrm{~N}\right]_{2}$-arginine: application to the response to vaccination. Am $\mathcal{F}$ Physiol 1997;272: R1888-96.

25 Rhodes P, Leone AM, Francis PL, et al. The L-arginine: nitric oxide pathway is the major source of plasma nitrite in fasted humans. Biochem Biophys Res Commun 1995;209: fasted

26 Green LC, Wagner DA, Glogowski J, et al. Analysis of nitrate, nitrite and ${ }^{15} \mathrm{~N}$ nitrate in biological fluids. Anal Chem 1982;126:131-8.

27 Brooks PD, Stark JM, McInteer BB, et al. Diffusion method to prepare soil extracts for automated ${ }^{15} \mathrm{~N}$ analysis. Soil $\mathrm{Sci}$ Soc Am Proc 1989;53:1707-11.

28 Hauck RD, Melsted SW, Yankwich PE. Use of N-isotope distribution in nitrogen gas in the study of dinitrification. Soil Sci 1958;86:287-91.

29 Gibaldi M, Perrier D. Pharmacokinetics: drugs and the pharmaceutical sciences. Vol 1. 2nd edn. New York: Marcel Dekker, 1982.

30 Smith EA, Macfarlane GT. Dissimilatory amino acid metabolism in human colonic bacteria. Anaerobe 1997;3 327-37.

31 Cunin R, Glansdorff N, Pierard A, et al. Biosynthesis and metabolism of arginine in bacteria. Microbiol Rev 1986;50 314-52.
32 Palmer RMJ, Ashton DS, Moncada S. Vascular endothelial cells synthesize nitric oxide from L-arginine. Nature 988:333:664-6.

33 Yu H, Sato EF, Nagata K, et al. Oxygen-dependent regulation of the respiration and growth of Escherichia coli by nitric oxide. FEBS Lett 1997;409:161-5.

34 Tannenbaum SR, Fett D, Young VR, et al. Nitrite and nitrate are formed by endogenous synthesis in the human intestine. Science 1978;200:1487-9.

35 Ioannidis N, Cooper CE, Poole RK. Spectroscopic studies on an oxygen-binding haemoglobin-like flavohaemoprotein from Escherichia coli. Biochem f 1992;288:649-55.

36 Crawford MJ, Goldberg DE. Role for the Salmonella flavohemoglobin in pro

37 Hausladen A, Gow AJ, Stamler JS Nitrosative stress: metabolic pathway involving the flavohemoglobin. Proc Natl Acad Sci USA 1998;95:14100-5.

38 Jungersten L, Ambring A, Wall B, et al. Both physical fitness and acute exercise regulate nitric oxide formation in and acute exercise regulate nitric oxide form
healthy humans. $\mathcal{F}$ Appl Physiol 1997;82:760-4.

39 Jung HC, Eckmann L, Yang SK, et al. A distinct array of proinflammatory cytokines is expressed in human colon epithelial cells in response to bacterial invasion. I Clin Invest 1995;95:55-65.

40 Salzman AL, Eaves-Pyles T, Linn SC, et al. Bacterial induction of inducible nitric oxide synthase in cultured human intestinal epithelial cells. Gastroenterology 1998;114:93102.

41 Witthoft T, Eckmann L, Kim JM, et al. Enteroinvasive bacteria directly activate expression of iNOS and NO production in human colon epithelial cells. Am F Physiol 1998;38: G564-71.

42 Islam D, Veress B, Bardhan PK, et al. In situ characterization of inflammatory responses in the rectal mucosae of patients with shigellosis. Infect Immun 1997;65:739-49.

43 Kolios G, Rooney N, Murphy CT, et al. Expression of inducible nitric oxide synthase activity in human colon epithelial cells: modulation by $\mathrm{T}$ lymphocyte derived cytokines. Gut 1998;43:56-63.

44 Rachmilewitz D, Stamler JS, Bachwich D, et al. Enhanced colonic nitric oxide generation and nitric oxide synthase activity in ulcerative colitis and Crohn's disease. Gut 1995; 36:718-23.

45 Kimura H, Miura S, Shigematsu T, et al. Increased nitric oxide production and inducible nitric oxide synthase activity in colonic mucosa of patients with active ulcerative colitis and Crohn's disease. Dig Dis Sci 1997;42:1047-54.

46 Singer II, Kawka DW, Scott S, et al. Expression of inducible nitric oxide synthase and nitrotyrosine in colonic epithelium in inflammatory bowel disease. Gastroenterology 1996; 111:871-85.

47 Kimura H, Hokari R, Miura S, et al. Increased expression of an inducible isoform of nitric oxide synthase and the an inducible isoform of nitric oxide synthase and the formation of peroxynitrite in colonic mucosa of
with active ulcerative colitis. Gut 1998;42:180-7.

48 McLaughlan JM, Seth R, Vautier G, et al. Interleukin-8 and inducible nitric oxide synthase mRNA levels in inflammatory bowel disease at first presentation. F Pathol 1997;181: 87-92.

49 Gupta SK, Fitzgerald JF, Chong SK, et al. Expression of inducible nitric oxide synthase (iNOS) mRNA in inflamed esophageal and colonic mucosa in a pediatric population. Am f Gastroenterol 1998;93:795-8.

50 Mourelle M, Casellas F, Guarner F, et al. Induction of nitric oxide synthase in colonic smooth muscle from patients with toxic megacolon. Gastroenterology 1995;109:1497-502.

51 Evans TJ, Buttery LD, Carpenter A, et al. Cytokine-treated human neutrophils contain inducible nitric oxide synthase that produces nitration of ingested bacteria. Proc Natl Acad Sci USA 1996;93:9553-8.

52 Albina JE, Caldwell MD, Henry WL Jr, et al. Regulation of macrophage functions by L-arginine. $\mathcal{F}$ Exp Med 1989;169: $1021-9$

53 Pacelli R, Wink DA, Cook JA, et al. Nitric oxide potentiates hydrogen peroxide-induced killing of Escherichia coli. F Exp Med 1995;182:1469-79.

54 Noronha-Dutra AA, Epperlein MM, Woolf N. Reaction of nitric oxide with hydrogen peroxide to produce potentially cytotoxic singlet oxygen as a model for nitric oxidemediated killing. FEBS Lett 1993;321:59-62.

55 Kubes P. Nitric oxide modulates epithelial permeability in the feline small intestine. Am f Physiol 1992;262:G113842 .

56 Duncan C, Dougall H, Johnston P, et al. Chemical generation of nitric oxide in the mouth from the enterosali-

57 McKnight GM, Smith LM, Drummond RS, et al. Chemical synthesis of nitric oxide in the stomach from dietary nitrate in humans. Gut 1997;40:211-14.

8 Dykhuizen RS, Frazer R, Duncan C, et al. Antimicrobial effect of acidified nitrite on gut pathogens: importance of dietary nitrate in host defense. Antimicrob Agents Chemother 1996;40:1422-5.

59 Mishima S, Xu D, Lu Q, et al. The relationships among nitric oxide production, bacterial translocation, and intestinal injury after endotoxin challenge in vivo. $\mathcal{F}$ Trauma 1998 ; 44:175-82.

60 Sorrells DL, Friend C, Koltuksuz U, et al. Inhibition of nitric oxide with aminoguanidine reduces bacterial translo-
cation after endotoxin challenge in vivo. Arch Surg 1996;131:1155-63.

61 Mishima S, Xu D, Lu Q, et al. Bacterial translocation is inhibited in inducible nitric oxide synthase knockout mice 
after endotoxin challenge but not in a model of bacterial overgrowth. Arch Surg 1997;132:1190-5.

62 Laubach VE, Shesely EG, Smithies O, et al. Mice lacking inducible nitric oxide synthase are not resistant to inducible nitric oxide synthase are not resistant to lipopolysaccharide-ind

63 McCafferty DM, Mudgett JS, Swain MG, et al. Inducible nitric oxide synthase plays a critical role in resolving intestinal inflammation. Gastroenterology 1997;112:1022-7. 64 Horton JW, White J, Maass D, et al. Arginine in burn injury
improves cardiac performance and prevents bacterial translocation. $\mathcal{F}$ Appl Physiol 1998;84:695-702.
65 Kubes P, Suzuki M, Granger DN. Nitric oxide: an endogenous modulator of leukocyte adhesion. Proc Natl endogenous modulator of leuk
Acad Sci USA 1991;88:4651-5.

66 Oudkerk Pool M, Bouma G, Visser JJ, et al Serum nitrate levels in ulcerative colitis and Crohn's disease. Scand $\mathcal{f}$ Gastroenterol 1995;30:784-8.

67 Hibbs JB Jr, Taintor RR, Vavrin Z, et al. Nitric oxide: a cytotoxic activated macrophage effector molecule. Biochem Biophys Res Commun 1988;157:87-94.

68 Roediger WE, Radcliffe BC. Role of nitrite and nitrate as a redox couple in the rat colon. Implications for diarrheal conditions. Gastroenterology 1988;94:915-22. 